\title{
Kantor está morto! Esqueçam Kantor!
}

\author{
Michal Kobialka
}

ala Preta: $\mathrm{O}$ teatro de Kantor tem como eixo um embate com a representação. Nesse sentido ele dialoga com dadaístas e surrealistas, mas também com outros criadores do teatro no século 20 que tiveram a crise da representação como um ponto de partida, como é o caso de Beckett. Eu desconheço qualquer menção de Kantor em seus escritos a Beckett. Ele conhecia bem o teatro de Beckett? Se conhecesse, seu silêncio a respeito seria estratégico? Como você relacionaria o trabalho dos dois?

Michael Kobialka: Esta é uma questão muito complexa. Eu penso que nós poderíamos estabelecer a relação entre Kantor, Beckett e outros artistas a partir da questão de como nós afirmamos a realidade, da questão de como a realidade pode ser representada. O fato de Kantor não fazer muitas referências a Beckett não implica que ele desconhecesse Beckett, mas que, se ambos tratavam dos mesmos temas, os materializavam de formas distintas. Eu penso que para Beckett, escrevendo nos anos 50 depois da II Guerra Mundial, a questão era o que significava representar, ou como representar a experiência da realidade que nos rodeia. Recordemos
Fim de Partida, quando nós temos quatro personagens, Hamm, Clov, Nell e Nagg, sendo que esses dois últimos são incapacitados de andar ou de agir na vida e, de alguma forma, sentem-se responsáveis pela condição em que se encontram naquele momento. Somente Hamm e Clov é que tentam lidar com aquela realidade que vêem lá fora, e, como sabemos, lá fora não há nada, é cinza. Este é Beckett. Não há progresso linear em Beckett. Da mesma forma como para as pessoas na situação do pós-guerra que não podiam ver progresso na história. Como podemos falar sobre progresso, que foi tão precisamente descrito por Kant em "O que é o Iluminismo", ou por Hegel, na teses históricas na década de 20 do século XIX, se o projeto do racionalismo iluminista terminou como terminou a II Guerra Mundial. Eu penso que Beckett, e ao mesmo tempo Kantor, se recusam a lidar com a História como um movimento progressivo, como um desenvolvimento em relação a algum tipo de final positivo. Não há tal final no horizonte. Só há esse momento em que eles estão tentando estabelecer como existir, de modo que a mente humana possa se dignificar depois de Auchwitz. Kantor e Beckett colocam

Michal Kobialka é professor da Universidade de Minessota. Esta entrevista foi concedida durante seminário internacional realizado pelo Programa de Pós-Graduação em Artes Cênicas da USP, em julho de 2005. A entrevista foi traduzida e editada por Luiz Fernando Ramos. 
no palco o mesmo problema, mas eles o materializam de modos completamente diferentes. Beckett com sua economia de linguagem, Kantor com seu desejo de expressar como os objetos podem ser pensáveis e identificáveis, e como seria possível não reduzi-los simplesmente a utilitários. Eu acredito que há todo um espectro de pessoas, uma gama de autores, pintores e filósofos que estão se colocando a mesma questão. E a questão é: o que significa representar quando o projeto iluminista fracassou. Como pode ser recordado, é Camus quem continuamente fala da necessidade de um auto-exame na cultura ocidental. Se você ler as teses de Hegel sobre a História, a civilização ocidental pressupõe o desenvolvimento do espírito até o nível mais avançado implicando na superação de um estágio primitivo das sociedades. Este era Hegel nos anos 20 do século XIX. Mas o que está acontecendo agora, politicamente, no pósguerra? É, exatamente, o mesmo processo. E é esse projeto que Beckett e Kantor se recusam a subscrever. Eles percebem, e querem nos fazer perceber, que se pode questionar a fé cega no progresso. Isto, num certo sentido, é o que nos é introduzido depois de 1968, na condição pósmoderna, na filosofia de Derrida, Foucault, Deleuze, Guattari, Michel de Certau, todos engajados em um questionamento sistemático do mito progressista do modernismo. Para resumir, eu penso que Kantor e Beckett, modernistas por excelência, realizaram um programa ético que o modernismo não acessava porque não havia as condições políticas que o requeressem.

Sala Preta: Kantor disse uma vez que os ensaios são a parte mais relevante do teatro, e só eles deveriam permanecer, mesmo quando não são bem-sucedidos, cheios de defeitos e necessitando de muitas correções, porque seriam a única arte verdadeira. Você poderia comentar essa afirmação?

Michael Kobialka: Em 1963 Kantor apresentou o que ele chamou de Exposição Popular. Em vez de apresentar obras de arte completas Kantor apresentou 963 objetos, que normalmente não são mostrados quando você se de- fronta com a pintura completa. Quer dizer, todos aqueles objetos utilizados no atelier e que são marginalizados frente à obra de arte pronta. Eu penso que nesse momento da jornada artística de Kantor a idéia de um processo se torna muito mais significativa do que a idéia do produto final. Ele opera dentro de uma cultura que só dá credibilidade ao produto final, que pode ser vendido, ou trocado. Nas Liçôes de Milão, particularmente a décima segunda, Kantor fala sobre o mercado dos museus, o mercado das galerias, e de como os museus e galerias dão visibilidade aos artistas. Em conseqüência disso, para que um artista visual obtenha reconhecimento é necessário que ele, ou ela, participe da globalização da imagem, de modo que em São Paulo, Minneapolis ou Varsóvia as pessoas possam reconhecer aquela imagem. Num certo sentido é um show ambulante. Kantor está, pois, ali chamando nossa atenção para o processo, isto nos anos sessenta, quando havia também o Living Theatre, o Open Theatre e o Performance Group, nos Estados Unidos, e outros tantos grupos em todo mundo interessados no processo, porque era ali onde as descobertas estavam acontecendo. Não acho que esteja dizendo nada novo sobre isso, mas Kantor, nesse momento, estava muito ligado a um contínuo processo de investigação na criação da obra de arte. Então ele mudou, e começou a mudar lidando com A Classe Morta e Wielopole, Wielopole. Contudo, e isso é um aspecto interessante, $A$ Classe Morta era supostamente uma obra de arte que estava continuamente se modificando. Depois de mil apresentações Kantor decidiu que não iria mais mostrar o espetáculo, porque algo que era pressuposto ser apenas um processo tinha se tornado uma obra arte completa. Há, então, um momento na trajetória do trabalho de Kantor em que $A$ Classe Morta deixa de ser apresentada pois passa a ser percebida como uma obra de arte concluída. Assim, o único modo de Kantor manter o frescor em torno de A Classe Morta era esquecer daquele espetáculo.

Sala Preta: Mas ela foi reencenada em Nova Iorque em 1991, não foi? 
Michael Kobialka: Isto foi depois da morte de Kantor, e curiosamente aquela montagem tinha doze minutos a mais do que a original, porque sem Kantor no palco tudo ficou mais solto. O tempo no teatro de Kantor é crucial. Os atores não tinham um ponto de referência.

Sala Preta: Os textos de Kantor publicados são muito peculiares, pois têm as falas, as rubricas e seus próprios comentários sobre a encenação. O que você poderia dizer a respeito.

Michael Kobialka: Existe uma relação estreita entre todos os elementos do processo criativo de Kantor. Se você pensa sobre suas produções, seus ensaios, seus desenhos, suas pinturas e suas notas, não como elementos separados, mas como modalidades singulares de uma senda artística, você percebe interconexōes entre todos eles. Quer dizer, seus textos estão estritamente conectados com seu pensamento, este com sua pintura e esta com as imagens de suas encenações. Articulados, eles criam uma rede extremamente sofisticada de interdependências. Qualquer texto de Kantor oferece um olhar acurado sobre o passado, o presente e o futuro. Algumas vezes Kantor escrevia o que chamava uma "partitura", que eram as notas sobre a produção, sobre o que ele estava pensando, sobre o que o estava observando. Então ele ia para o ensaio e iria escrever que tudo que ele tinha escrito na noite anterior não fazia nenhum sentido no espaço da cena. O que acontecia no espaço da cena era também registrado por Kantor durante o processo de ensaio e é possível perceber a tensão entre aqueles dois textos diferentes. Simultaneamente, há um comentário permanente, porque um ator provoca um pensamento em Kantor, que será registrado em pedaço de papel ou expresso numa pintura, ou numa peça em que ele está trabalhando. É uma idéia de Gesamtkunswerk (obra de arte total) num modo muito particular, pois você não pode separar aqueles elementos, sendo eles todos interdependentes, no sentido que eles materializam o pensamento de Kantor de maneiras diferentes, mas dentro de todo um espectro de possibilidades. Esta é uma razão porque, freqüentemente, mes- mo quando a produção estava completa Kantor acrescentava novos elementos à partitura. Ou realizava um desenho que era necessário a uma produção realizada vinte anos antes. Por isso temos que ser muito cuidadosos quando vamos datar os desenhos e os textos de Kantor. Ele precisava de desenhos para a produção de $O$ Retorno de Odisseu, de 1944, e alguns desses desenhos só foram efetivamente realizados em 1980 . Isto nos leva a pensar em um tempo total, significando que o que aconteceu em 44 reaparece para Kantor em 1988, quando estava trabalhando em Eu que não deveria voltar jamais, e aqueles textos retomavam o que ele pensava mais de quarenta anos antes. Na peça Kantor encontra Odisseu, senta com ele na mesma mesa e lê de seu caderno de direção, que tinha sido criado em 1944. Mas aquelas palavras soam agora de uma forma totalmente diferente. Há comentários, desenhos de cena, a linguagem da poesia. O processo do pensamento não possui um tempo rígido, a consciência não conhece o tempo, e se você pode pensar sobre isso como uma infatigável e contínua investigação além dos confins do tempo e do espaço, essa será minha resposta. É difícil. Como Kantor disse em 1990, em um de seus diários mais íntimos, "talvez quando eu morrer eu pare de pensar”. Pareceme que essa modalidade, o pensamento, é sempre extremamente dinâmica. Todos nós sabemos apreciar um repouso. Para ele não havia repouso. Portanto, tudo aquilo que estava acontecendo, pinturas, desenhos, escritos e produções, eram a materialização da mesma obsessão de pensamento. Um pensamento que nunca repousava.

Sala Preta: Uma das características do teatro de Kantor é associar de forma estreita as dimensões ética e estética. Como você analisa estes aspectos?

Michael Kobialka: No fim das Liçôes de Milāo, Kantor diz: "Lembrem de tudo e esqueçam de tudo". E eu penso que esta afirmaçãoo descreve o paradoxo que define o teatro de Kantor. Kantor entende a ética como a idéia da nomeação do vazio. $\mathrm{O}$ vazio é aquilo que não 
tem um modo preciso de ser descrito, ou escapa do nosso campo de apreensão da realidade. Kantor não está interessado necessariamente na mimese oficial, no modo oficial de representação da realidade. Mas ele está muito interessado naqueles elementos que escapam daquela realidade oficial. Nós chamamos isto de nada, de vazio, alguma coisa que não pode ser vista. Para Kantor este nada, ou vazio, é o que ele quer investigar, porque mesmo se esta busca for inútil, para ele aquele vazio está precisamente liberado das constrições da realidade presumida. A realidade é o que nós somos autorizados a pensar sobre ela, a linguagem que nós temos para descrevê-la. O que ele quer fazer? Ele quer perturbar essas legitimações, que descrevem a emergência da realidade, nomeando o vazio. Nesse sentido o nomear o vazio é a ética de Kantor, de descrever como os elementos estabelecem suas individualidades, estabelecem suas características, não por conta do valor de uso alocado sobre eles pela sociedade e pela cultura, mas pelas relações que estão sendo estabelecidas entre determinados elementos em um espaço determinado. É só quando você se engaja neste processo que você pode realmente desafiar os mitos que nos rodeiam. Há uma razão porque no teatro de Kantor nós estamos continuamente lidando com a repetição: as coisas são repetidas, os mortos voltam à vida, as situações são recriadas de novo, não porque ele quer preencher o tempo em suas produções, mas porque, como ele diz, talvez essa repetição finalmente nos permita ver aquele evento como se fosse pela primeira vez, de modo que nós possamos mudálo. O movimento circular não é circular, porque toda vez que ele se repete, talvez, haja um novo aspecto que está sendo trazido à atenção. Há um buraco, para ele. Em Noite Silenciosa, uma cricotage de 1990, Kantor mostra o mundo depois de uma catástrofe e indica que quando as pessoas voltam à vida, como no seu teatro, mui- to rapidamente elas começam a reconstruir, primeiro os eventos bíblicos, o mundo transcendental, depois as rotinas diárias e finalmente os eventos históricos. E essa reconstrução do mundo terminará gerando um novo desastre. E começamos de novo. Kantor permanece colocando a questão sobre quantas vezes vamos ter que fazer para finalmente nos dar conta do que é que estamos fazendo. E para mim esta é a ética do que eu chamaria de teatro político. Quer dizer, quantas vezes nós temos que ver um genocídio para entender um genocídio. E isso é exatamente o que Kantor está indicando. Giorgio Agamben, comentando os acontecimento da Auschwitz fez uma bela colocação: "É hipócrita se perguntar como Auschwitz pode acontecer. Como Ruanda pode acontecer. Nossa responsabilidade é perguntar quais são as condições que nós criamos que permitem que esses acontecimentos continuem se repetindo". ${ }^{1}$ E este é o teatro de Kantor. Ele fala sobre as condições existentes que permitem que esses acontecimentos se dêem sem desafiar os próprios atos que levas esses fatos a acontecerem. Para mim este é o aspecto ético da investigação de Kantor. Não como isso pode acontecer, mas quais as condiçōes que estão sendo perpetuadas, que nós continuamos mantendo e nos fazem caminhar ao encontro de um novo desastre.

Sala Preta: Não lhe parece que a memória em Kantor é uma antimemória, ou uma antimemória no sentido platônico, não como reminiscência do que já se sabia mas como apresentação de uma nova realidade. Como você vê essa questão da memória em Kantor?

Michael Kobialka: Se eu tivesse que utilizar Platão para discutir a memória, ou mesmo Santo Agostinho, qualquer um dos dois, seja com a idéia das sombras ou das impressões, isto significaria o processo de recuperar certos acontecimentos ou pessoas à consciência. Você deve recordar a história de Simonides, com quem a

1 AGAMBEN, Giorgio, Remnants of Auschwitz: The Witness and The Archive. Trad. de Daniel HelleRoazen. New York: Zone Books, 1999. 
arte da memória nasceu. Depois de ir a um Banquete, e retirar-se, a edificação onde estivera vem abaixo e todos os presentes são soterrados a ponto de ficarem irreconhecíveis. Simonides é chamado para ajudar os parente a identificar os cadáveres. Reconstituindo de memória o lugar em que cada um dos presentes encontravase sentado, Simonides foi capaz de identificar os mortos. A idéia de relembrar mentalmente algo que aconteceu é uma idéia que obviamente coloca os mortos, ou o passado, ao longo de um tipo de itinerário que dá a essa memória, algo que é efêmero, uma presença. Dando presença a algo que é efêmero, nós o fixamos e o estabilizamos, transformando-o numa memória morta. Num certo sentido, relembrar mentalmente é o momento de destruir as memórias, porque nós só lembramos do que pode ser expresso de uma maneira particular. Você é quem dá visibilidade aos mortos. Esta é uma metáfora utilizada por Michel De Certeau em The Writting of History ${ }^{2}$ para falar de como nós os historiadores forçamos os corpos mortos a falar nossa língua. É só fazendo-os falar nossa língua que os mortos ou as memórias se tornam visíveis a nós. Nesse sentido as memórias não são memórias, mas só mortos que nós não conseguimos entender. Eu penso que Kantor está muito consciente disso, e ele está desafiando a autoridade de quem está recordando. O que eu recordo, como eu recordo. É sempre um ato ético e político. A memória das naçôes. Eu posso pensar na situação na Polônia, e de como os mitos nacionais poloneses são lembrados. Eu posso pensar em qualquer outro país do mundo e de como as memórias nacionais são usadas para justificar as expansões territoriais, a erradicação de grupos minoritários etc. Está sempre acontecendo e veio acontecendo ao longo dos séculos. Eu penso que esta é uma das razóes porque Kantor não quer subscrever este tipo de mnemotécnica, ou a técnica da memória, sugerindo o contrário, quer dizer, o que está encoberto para que esta memória se faça visível. Assim Kantor quer lembrar mentalmente e mostrar no palco aquilo que a memória encobre e apaga da vista. Esta é uma das razões porque ele é obcecado com a idéia de que criar memórias é um processo dinâmico que nunca se estabiliza. Um processo que está continuamente sendo exibido, como ele faz em $A$ Classe Morta, em que é necessário se certificar de que nossas memórias do passado nunca estarão completas, mas que serão sempre perturbadas por algo que nos queremos pôr de lado, para que possamos esquecer pois não são convenientes. Assim em $A$ Classe Morta, as memórias dos dias de escola poderiam, no fim, ser fonte de prazer. Mas o que ele faz ali, trazendo para dentro daquelas memórias personagens como o do soldado da primeira guerra mundial, é impedir que as memórias criadas pelos velhos se completem. Então é um processo de perfuração das memórias, de desestabilização delas. É um processo de fazer brotar uma memória e em seguida deixar que ela colapse. Mas é uma imagem que nunca se completa. O mesmo é verdade para suas memórias da segunda guerra mundial e de sua família. A questão é como lidamos com a memória. Então isso nos permite entrar em regiōes que são autônomas, em vez de eu dar a esta memória uma linguagem, de modo que os mortos sejam os mesmos que eu sou. Em um de seus ensaios Kantor diz que a memória é como a realidade. Se eles são ambos iguais então é precisamente com a tensão entre eles que Platão não pode lidar, que Santo Agostinho não pode lidar. Contudo, a existência destes universos paralelos é exatamente o momento em que o teatro se torna um lugar de transição, de um mundo para o outro. Assim a memória é tão real como qualquer outra coisa.

Sala Preta: Seria possível dizer que Kantor, de um ponto de vista estrito nunca foi esté-

2 DE CERTEAU, Michel. The Writing of History. New York: Columbia University Press, 1988. 
tico, se tomarmos a idéia kantiana da estética de uma recepção desinteressada.

Michael Kobialka: Certamente. Não há possibilidade de não ser parte interessada. Se eu digo que para mim a função do teatro é responder à realidade isto define completamente minha atitude frente a esta realidade. Não há outro modo de pensar isso. Assim desinteresse não existe para Kantor, é impossível. Estar desinteressado, eu acredito, para ele significaria estar morto ou não existir. Não há jeito, para Kantor, de não se estar envolvido com a realidade. $\mathrm{O}$ que é interessante é que em 1952, antes do estabelecimento de Cricot 2, Kantor participou ativamente de discussões na Polônia sobre o futuro da arte polonesa. Este era o tempo do realismo socialista, e o aspecto interessante desta discussão era que, até um certo ponto, o que Kantor propunha como arte poderia ser visto no âmbito da estética do realismo socialista, lidando com a realidade. Contudo, ele esteve em diversas reuniōes em que brigou pela autonomia dos artistas explorarem uma realidade concreta, em vez de subscrever uma certa apropriação temática daquela realidade. Assim, ele sempre esteve engajado na tarefa de lidar e perturbar aquela realidade em que ele se percebia. E eu penso que este é precisamente o aspecto de seu teatro que julgo extremamente importante tocar. Quer dizer, Kantor está sempre lidando com o encontro com algo externo que o faz pensar, com o encontro com o outro, e se força não a colonizar o outro, mas a se autoexaminar e a examinar suas relações com aquele outro. Esta prática teratológica é uma prática radical e sempre dinâmica.que, eu sugiro, integra tanto sua ética como sua estética.

Sala Preta: E sobre a relação entre Kantor e Grotowski?

Michael Kobialka: Muito resumidamente. A confusão que ocorre freqüentemente é que os dois fazem referência a um Teatro Pobre. Essa palavra pobre, esse adjetivo significa um modo de lidar com o teatro e é precisamente aí que está a diferença. Para Grotowski o teatro pobre refere-se a estabelecer um processo que retira do teatro todos os elementos desnecessários para que a representação ocorra. Eis porque o cenário, o figurino e a luz são reduzidos e o palco fica vazio. Grotowski está muito consciente que nesse processo de limpeza, o que está sendo revisto é o elemento mais poderoso do teatro que é o movimento do corpo no espaço. Em vez de cobri-lo com figurino, maquiagem e luz, deixeme mostrar a vocês a força deste corpo se movimentando no palco. Este é o teatro pobre de Grotowski. Para Kantor, está conectado com o fato de que quando ele está trabalhando com $O$ Retorno de Odisseu, em 1944, a bestialidade da guerra força-o a desafiar todas as convençôes associadas à civilização que levou àqueles eventos. É a idéia de que uma nova realidade requer uma nova linguagem. Se eu uso a mesma linguagem aquela realidade continuará operando. Se, contudo, aquela realidade é o que estou desafiando eu preciso encontrar uma nova linguagem para descrever o que acontece. No teatro de Kantor durante a guerra encenar uma peça em um teatro era participar da procriação ou perpetuação da convenção tradicional. Essa é uma das razões porque ele não pode fazê-lo, além do fato que qualquer atividade artística na Polônia à época era punida com a pena de morte pelos nazistas. Assim o único lugar em que ele podia fazê-lo era um lugar que estivesse fora da situação oficial e normativa. E esse era um lugar que não mais pertencia à civilização. Estava dentro dela, mas tinha sido destruído pela civilização e se tornado inútil, sendo excluído da norma. Eis porque Kantor vai utilizar este quarto (nos escombros de um prédio bombardeado). $\mathrm{O}$ mesmo se aplica aos atores que entravam nesse espaço. Na Polônia, um ser humano estar vivo era um transtorno. Supunha-se que você estivesse morto. Se você ainda não está morto eu o quero morto. $\mathrm{O}$ aniquilamento da Polônia, um país com maioria de judeus, era um objetivo claro. Portanto a ação de um ser humano neste quarto era um ato fora da norma. O mesmo é verdade para o que os atores traziam. Não são mais adereços, são objetos inúteis, destruídos pela guerra. Portanto nesse sentido o teatro de Kan- 
tor é também um teatro pobre, mas não no sentido de Grotowski. As bases são completamente diferentes. Por exemplo, não há metodologia no teatro de Kantor. Grotowski deixa um método, uma série de exercícios que podem ser usados pelos atores para criar um resultado muito particular. Uma vez que Kantor está morto, o seu teatro desaparece. Não há um método Kantor. Há atores que entendem o que Kantor fez e criam espetáculos, mas são espetáculos que lidam mais com as individualidades de seus agentes do que com um método de atuação. Ambos criaram estruturas teatrais muito autônomas e heterogêneas. Ambos que criaram teatros pobres, mas as respectivas pobrezas são associadas a condições materiais, físicas, éticas e estéticas completamente diferentes.

Sala Preta: E como era a relação entre os dois? Eles se conheciam?

Michael Kobialka: Sim eles se conheciam. Grotowski ia aos espetáculos de Kantor. Não estou certo de que Kantor fosse aos espetáculos de Grotowski.. Grotowski era mais moço. Há muitas histórias sobre os dois. A relação era muito complexa. Eu penso que o mais interessante é que eles eram tão diferentes que não chegava a haver uma competição entre eles. Havia um reconhecimento mútuo nos termos da arte do teatro e da teatralidade. Mas eu não acredito que jamais pudessem trabalhar juntos. Eu não posso imaginar isto e essa impossibilidade é o melhor retrato dessa relação. Mas sim, eles se encontravam. Depois da morte de Kantor e da morte de Grotowski houve algumas tentativas, da parte de pesquisadores de seus respectivos centros de documentação, de fazer alguma coisa juntos, tentando estabelecer, na forma de uma investigação dos arquivos, a significação de suas práticas teatrais.

Sala Preta: Você mencionou a repetição como uma tentativa de evitar que se perpetue o desastre, na idéia da história como memória coletiva. Você fala sobre memória e parece que você está falando numa memória que se perpetua e na linguagem como uma categoria avassaladora.
Michael Kobialka: Exatamente. Eu penso que para Kantor a idéia de uma memória coletiva é algo que deve ser perturbado. Em um de seus ensaios sobre sua trajetória pessoal ele diz ter sempre estado contra os movimentos de massa, contra as ideologias de massa. E não era só porque ele não acreditava em alguma ideologia particular, mas porque ele está muito consciente de como ideologia podem resultar em burocracias. Ele é radicalmente contra o socialismo burocrático. Nesse sentido, o que ele está querendo propor é que uma necessária condição para manter a autonomia do artista, e não estamos falando da idéia romântica de artista como um criador messiânico, é a sua vida individual que desafia o que parece relevante a esses movimentos de massa. Então esse é o poder, a força e a condição necessária. Na produção de Noite Silenciosa, Kantor confrontou a memória coletiva da Polônia com a tendência do país a esquecer-se de tudo. Naquela época não havia a possibilidade de se admitir a existência de minorias na Polônia, e por um longo tempo sustentou-se a idéia de que se tratava de um país homogêneo. Não havia minorias. Kantor diz: "Desculpem-me, isto tem que ser perturbado". Assim, a memória coletiva não significa necessariamente uma memória que tem que ser perpetuada, mas uma memória que foi construída através da ideologia de massa. Não me compreenda mal, mas penso que ele empreende um esforço contínuo para torcer, enrugar, algo que vai se tornando uma superfície lisa. Ele está, nessa medida, encenando uma greve na casa da história. Ainda que a história possa ser vista como em progressão, nessa casa ele está encenando uma greve. Ele não sairá, ele não vai se satisfazer. Essa é uma condição necessária para ele.

Sala Preta: Como você relacionaria o teatro de Kantor com a tradição simbolista e com as idéias de Maeterlink de um teatro de andróides?

Michael Kobialka: No Manifesto do Teatro da Morte, Kantor escreve bastante sobre Craig e sua idéia de que precisamos nos livrar dos atores porque eles destroem o teatro. Essa 
seria uma das razóes pela qual, no teatro de Craig, a marionete substitui o ator, e o mesmo é verdade para os simbolistas e sua idéia de desteatralização, do pressuposto de querer mostrar o que se pode pensar mais do que as emoções do ator. Nos dramas de Maeterlink e de Yeats a idéia é: deixe-me mostrar no palco o que você pensa. Mas este pensamento só pode ser mostrado numa perspectiva antiteatral. Lembre-se que o palco simbolista é sombreado, os atores se movem pouco e só há as palavras que são ditas, evocativas de imagens que, se supõe, serão despertadas no espectador. Uma marionete é, pois, um elemento perfeito para desteatralizar a cena. Kantor até um certo ponto concorda com esse projeto, com essa idéia. Contudo, ele indica que essa tentativa de nos afastar da tradição teatral se realiza de maneiras diferentes, em diferentes momentos da história. Marcel Duchamp e Dada, por exemplo, também tentaram desteatralizar o espaço tradicional introduzindo a realidade do "ready-made", uma realidade que estava despida de ilusão. Em uma das seções do manifesto do Teatro da Morte, Kantor afirma que o problema do ator não é que ele se movimenta no palco, ou que sente emoções, mas que o ator, de alguma forma, perpetua aquele entendimento particular do teatro. Assim, qualquer coisa que possa perturbar aquela compreensão do teatro, entendido como um processo de ilusão, e desteatralize a ilusão, terá significação para Kantor. Seja uma marionete como no caso de Craig, ou objetos encontrados - "readymade", como em Duchamp. São ambos processos de destruição da ilusão. Mesmo assim, ele salienta, esse processo de introduzir uma "realidade pronta" como forma de desteatralizar a ilusão que supostamente é criada pelo ator, de alguma maneira fracassou. De fato, quando uma audiência assiste a um happening, participa dele como se aquela apresentação lhe propiciasse criar uma ilusão de ação. Ele dizia: o happening no começo provocava um choque na audiência, até que se tornasse um modismo e se tornasse previsível. Pense em Dionísio 69 e no Living Theatre. No começo chocava o público, mas depois se tornou tão óbvio que o público já ia ao teatro preparado para participar de algo pouco usual. Assim aquela participação que pretendia, no início, chocar tornava-se uma participação no ato estético. Então o que seria possível fazer para perturbar isso? A resposta foi a noção do Teatro da Morte, em 1975. Separavase a audiência dos atores criando a "barreira intransponível”. Portanto, a marionete, ou o manequim, no teatro de Kantor, naquele momento, é a imagem que de algum modo nos é familiar, mas, ao mesmo tempo, é estranhamente diferente e separada, em oposição ao teatro tradicional em que o ator é uma extensão da pessoa sentada no auditório, interpretando as personagens de uma peça, que é uma imitação da vida. Para ele há a barreira instransponível. Enquanto o público quer se ver refletido na cena, Kantor está negando-lhe este conforto, tentando chocá-lo. Não há satisfação instantânea garantida. Assim, colaboram na sua idéia de utilizar a marionete, a referência de Craig, bem como sua insatisfação com os happenings, mas Kantor está também muito consciente da tradição simbolista. Ele encenou, em 1938, A Morte de Tintagiles, de Maeterlink, e voltou à peça em 1988, com o espetáculo A Máquina do Amor $e$ da Morte, um espetáculo maravilhoso. Nele usava as marionetes de uma maneira construtivista. Inclusive, nos anos trinta tinha criado um teatro de bonecos, porque era fascinado pela tradição simbolista que conhecia muito bem. 